\title{
Comparison of second-degree and traditional baccalaureate nursing students' performance in managing acute patient deterioration events
}

\author{
Eileen Mary Cormier , James Whyte IV \\ Florida State University College of Nursing, Tallahassee, Florida, United States
}

Received: September 24, 2015

DOI: $10.5430 /$ jnep.v6n8p138
Accepted: November 12, $2015 \quad$ Online Published: April 12, 2016

URL: http://dx.doi.org/10.5430/jnep.v6n8p138

\begin{abstract}
Background: Students in accelerated second-degree programs are reported to be highly motivated, older, competitive, maintain higher grade point averages than their traditional counterparts, and score higher on standardized nursing achievement tests. However, studies that directly measure clinical performance parameters of students in accelerated second-degree programs in direct side-by-side comparison with traditional students under similarly controlled conditions have not been reported.

Aim: The purpose of this study was to compare traditional and second-degree baccalaureate nursing students' performance of key assessments and interventions in the management of deteriorating patients in a simulated task environment.

Methods: A convenience sample of 20 traditional and 20 accelerated undergraduate baccalaureate-nursing students participated. The four high-fidelity simulation exercises required the participants to detect early signs of patient deterioration and initiate treatment-based interventions. Two research personnel independently coded audio and videotaped data. The coders recorded the first time in which an assessment or intervention was performed. An independent samples $t$-test was performed to determine differences in nursing students' performance of key assessments and interventions.

Results: Second-degree accelerated nursing students were in general more likely to recognize and respond to indicators of patient deterioration more promptly than their traditional counterparts.

Conclusions: Second-degree students appear to possess attributes that increase the likelihood that they will appreciate stimuli in the clinical environment, which is a precursor to effective intervention. Further research is required to substantiate the factors that account for performance differences between these traditional and second-degree baccalaureate nursing students.
\end{abstract}

Key Words: Patient deterioration, Nursing student, Simulation, Clinical performance

\section{INTRODUCTION}

The growth of accelerated second-degree programs of study in nursing has proliferated in response to the global shortage of registered nurses in the workforce and the increased need for skilled care providers. ${ }^{[1,2]}$ These programs target students with a baccalaureate degree in another field and provide them the opportunity to receive a nursing education and begin working in a shortened time frame, generally 12 to 18 months. The curriculum is intense and students receive the same number of clinical hours as their counterparts in traditional programs. The accelerated second-degree program is designed to capitalize on the students' prior life and

\footnotetext{
${ }^{*}$ Correspondence: Eileen Mary Cormier; Email: ecormier@fsu.edu; Address: Florida State University College of Nursing, Tallahassee, Florida, United States.
} 
learning experiences and transition them into a career as a professional nurse. $^{[3]}$

The literature affirms that students who enroll in accelerated second-degree programs are highly motivated, older, competitive, maintain higher grade point averages than their traditional counterparts, and score higher on standardized nursing achievement tests, including the NCLEX-RN. ${ }^{[4-8]}$ It has also been reported that second degree nursing students prefer adult-learner oriented teaching strategies that are experiential and context-based, such as clinical simulations and interactive technologies, relative to traditional students in baccalaureate programs, who prefer more structured, didactic approaches. ${ }^{[9-11]}$ Evidence of quantifiable differences in clinical performance between second degree and traditional nursing students, however, is less forthcoming. Second degree students were shown to perform higher than traditional undergraduates on a knowledge-based post-test in a mock code in a simulation lab, ${ }^{[12]}$ but studies that directly measure clinical performance parameters of students in accelerated second-degree programs in direct side-by-side comparison with traditional students under similarly controlled conditions have not been reported.

Accelerated second-degree nursing programs present unique challenges to educators to prepare graduates who meet entryto-practice competencies within an abbreviated time frame, alongside their traditional baccalaureate counterparts. ${ }^{[13,14]}$ The increasing acuity and complexity of patients requires new graduates to provide care for seriously ill patients in acute care hospitals when they graduate much earlier than was seen in the past. ${ }^{[15]}$ Caring for critically ill patients entails recognizing and interpreting indicators of a deteriorating condition, and task prioritization to mitigate adverse outcomes. ${ }^{[16]}$ Literature suggests that many new graduates regardless of nursing program fail to demonstrate the clinical reasoning skills required to detect deviations from normal physiologic findings and initiate nursing actions essential to validate problems or prevent acute deterioration events from getting worse. ${ }^{[15,17]}$ When faced with complex or unfamiliar clinical situations, novice nurses often respond by focusing on single tasks or problems, psychomotor skills, or learned interventions rather than enacting decision-making based on situational perception and comprehension of the multidimensional nature of the situation. ${ }^{[16,18]}$

The increasingly complex and unpredictable nature of contemporary practice environments and competing demands for quality clinical placements make it difficult for accelerated second-degree nursing programs to provide learning opportunities that develop the higher order clinical decisionmaking skills that are required for navigating the problematic situations students will encounter in real-life clinical practice. ${ }^{[19]}$ The quality of nursing education is highly dependent on the quality of the clinical practice learning experiences provided to students. Contemporary educational approaches emphasize the need for active learning and advocate the use of simulated environments with high technological, environmental and psychological fidelity to reduce medical errors. ${ }^{[17]}$ The American Association of Colleges of Nursing ${ }^{[4]}$ supports the practice of augmenting clinical practice with high fidelity simulation because it provides students with the opportunity to gain mastery in specific skills through deliberate practice in a safe and controlled environment. A growing body of literature provides evidence that high fidelity simulation improves knowledge acquisition and critical thinking of undergraduate nursing students, ${ }^{[20]}$ as well as self-efficacy and learner satisfaction, ${ }^{[21-23]}$ and that the knowledge and skills gained from simulation practice transfers directly to the point of care. ${ }^{[22,24,25]}$ Consistent with the literature, students in accelerated baccalaureate programs engaged in high fidelity simulation report learner satisfaction and increased self-efficacy and competence for clinical practice. ${ }^{[26,27]}$

A key challenge in the integration and use of high fidelity simulation in nursing curricula is the measurement and evaluation of clinical competencies. Although the quality of quantifiable outcomes in the simulation literature has improved in recent years, the majority of studies of high fidelity simulation remain descriptive with a focus on student and faculty perceptions versus measurable outcomes. ${ }^{[28]}$ Those that employ objective measures of clinical competence use variable approaches to measurement and report inconsistent findings. ${ }^{[29-31]}$

There is a paucity of research examining differences in clinical performance attributes of traditional and accelerated nursing students in high-fidelity simulated task environments. As nurse educators seek evidence to support and guide changes in educational pedagogies for accelerated second degree programs related to the best use of high-fidelity simulation, it is important to examine differences in clinical performance and explore the degree of equivalence between traditional and second-degree nursing programs.

The present study was part of a larger pilot study that evaluated the efficacy of a deliberate practice based educational intervention designed to enhance the clinical performance of student nurses. In an effort to better understand the performance of traditional and accelerated second degree nursing students confronted with urgent care situations, the investigators assessed and compared their ability to recognize and respond to patient deterioration in a high fidelity simulation environment. The study employed quantitative measures of 
nursing students' ability to identify key situational elements and initiate actions that were more likely to elicit favorable physiologic outcomes for unstable patients in a critical care environment.

\section{Aim}

The aim of this study was to compare the performance of key assessments and interventions between traditional and second-degree baccalaureate nursing students. More specifically, the research question was: How do second-degree baccalaureate nursing students differ from traditional baccalaureate nursing students in their ability to recognize and respond to salient stimuli in the management of deteriorating patients in a simulated task environment?

\section{METHOD}

\subsection{Simulation protocol and setting}

Four simulation exercises involving an acutely ill patient were developed by the investigators and tested extensively for validity and stability prior to use in the current study. The exercises were designed to encompass multiple principles involved in the care of the critically ill. The scenarios included: 1) a patient experiencing acute hypotension and receiving a dopamine infusion; 2) a patient suffering from acute sepsis, with hypotension, on a norepinephrine infusion; 3) a patient who had fallen, resulting in a closed head injury with subsequent hypertensive crisis; and 4) a patient who had undergone recent abdominal surgery and was experiencing post-operative hemorrhage.

The simulation exercises were situated in the time frame that a nurse enters a patient's room to perform an initial assessment, respond to an alarm, or answer a patient's call for assistance. They involved situations in which the nurse would lack extensive information regarding a patient, such as at shift change or during a period when the patient's primary nurse is off the unit. That is, the scenarios were designed to challenge the participant with poorly defined patient problems, requiring more extensive assessment of the simulated patient. Although all relevant information was available in the room, including a patient record, the scenarios required the participant to determine what assessment and treatment-based interventions were necessary on the basis of the patient's presenting condition. This served to increase the complexity of the individual scenarios, while offering a clearer opportunity to differentiate performance. Finally, the exercises simulated situations where the participant had the opportunity to identify cues indicative of acute deterioration and act to prevent patient demise. Most importantly, each of the clinical scenarios was developed so that it was reproducible under the controlled standardized conditions of 140 a simulated task environment (STE).

The study was conducted in a STE configured to emulate an acute care hospital patient room in a 'telemetry plus' setting. The METI ECS @Human Patient Simulator (HPS) adult model was used. The HPS recorded, at 5-second intervals, physiologic parameters such as mean blood pressure, pulse (MABP), central venous pressure, pulmonary artery pressure, and oxygen saturation (O2Sat). The STE was equipped with 3 -angle video and high fidelity audio and video recording equipment for collecting direct observation (participants' actions) and concurrent verbal report data (thought processes underlying actions and decisions) within the clinical scenario that could be coded. Research personnel were able to control the simulation out of view of participants from a soundproof observation room.

\subsection{Sample}

The nonrandom sample of 20 traditional and 20 accelerated undergraduate baccalaureate nursing students was recruited from a College of Nursing (CON) in a large public research university located in the southeastern United States. Human subjects committee approval for the study was gained prior to recruitment. The students were invited to participate by the research team at a 5-minute information session about the project at the end of their second semester and emailed the Principal Investigator (PI) to convey their interest. Hence, at the time of the study, the nursing students were beginning the third semester; all had completed courses in nursing fundamentals, health assessment, pharmacology, adult health and mental health nursing with associated clinical experiences.

\subsection{Data collection and procedures}

Participants were tested in private with only the investigators present. Prior to entering the STE, they completed an informed consent and a demographic survey designed to collect information on demographic, educational, professional and experiential characteristics of participants. ${ }^{[32,33]}$ Participants then received instruction in providing concurrent verbal reports. ${ }^{[34]}$ Also referred to as "thinking aloud", concurrent verbal reports are the verbal communication of thoughts related to clinical actions provided by participants delivering patient care within the STE. Verbal reports provide a quantifiable measure that is representative of the cognitions underlying nurses' actions. The procedures for training participants to give verbal reports had been trialed on participants in multiple studies at the research site. ${ }^{[33]}$ Following "thinking aloud" training, participants were oriented to the STE and process for completing the simulation exercises, and then engaged in the simulation exercises while furnishing a concurrent verbal report. 


\subsection{Data processing and analysis}

Sources of data were the Demographic Survey, concurrent verbal reports (audio-recorded), and direct observation of participants' actions (video-recorded). These recordings were viewed and coded by two independent research personnel who had been trained to code video data by experienced research staff. The coders recorded the first time in which an assessment or action was carried out in the simulation exercise. Following independent coding, comparisons were made between the coded data. A third coder then reconciled the transcript of assessment and interventions observed by reviewing the portions of the recording where differences existed. This resulted in a true-to-life transcript of all assessments and interventions, including the exact time that participants performed key assessments and actions. An independent samples $t$-test was performed to determine differences in nursing students' performance of key assessments and interventions.

Table 1. Demographic characteristics

\begin{tabular}{ll}
\hline Characteristic & Mean/Percentage \\
\hline Age (N = 20) & $27.70($ SD 9.29$)$ \\
Traditional & $22.67(\mathrm{SD} .492)$ \\
Second Degree & $35.25(\mathrm{SD} 11.18)$ \\
Gender & \\
Male & $20 \%(\mathrm{~N}=4)$ \\
Female & $80 \%(\mathrm{~N}=16)$ \\
Program & \\
Traditional & $60 \%(\mathrm{~N}=12)$ \\
Second Degree & $40 \%(\mathrm{~N}=8)$ \\
Cumulative GPA & $3.69(\mathrm{SD} .14)$ \\
Traditional & $3.70(\mathrm{SD} .12)$ \\
Second Degree & $3.66(\mathrm{SD} .15)$ \\
Nursing GPA & $3.74(\mathrm{SD} .19)$ \\
Traditional & $3.70(\mathrm{SD} .18)$ \\
Second Degree & $3.81(\mathrm{SD} .19)$ \\
Race/Ethnicity & \\
White & $80 \%(\mathrm{~N}=16)$ \\
African American & $10 \%(\mathrm{~N}=2)$ \\
Asian & $5 \%(\mathrm{~N}=1)$ \\
Hispanic & $5 \%(\mathrm{~N}=1)$ \\
Allied Health Certification & \\
Certified Nursing Assistant & $20 \%(\mathrm{~N}=4)$ \\
Emergency Medical Technician & $0 \%$ \\
Licensed Practical Nurse & $0 \%$ \\
\hline
\end{tabular}

\section{RESUlts}

Table 1 reports the demographic characteristics of the accelerated second degree and traditional baccalaureate participants are presented in Table 1 . The groups differed primarily with regards to age, with the second-degree students being approx- imately 10 years older on average. Notably, the traditional students had higher cumulative grade point averages, with the second-degree students having higher nursing specific grade point averages. The participants, aside from four who had completed nursing assistant courses, lacked significant healthcare-related experience.

A pre-hoc informal task analysis was conducted to establish the nursing observations and actions that were seen as desirable for the purpose of coding and comparative analysis. These tasks were primarily evaluative versus treatmentfocused actions. Table 2 presents differences in participants' performance of specific tasks and their time of occurrence in seconds for Trial 1 and Trial 2. In Trial 1, involving care of an acutely hypotensive patient receiving a dopamine infusion, there were no statistically significant differences between the second-degree and traditional baccalaureate participants in the time they required to perform key assessments and actions. However, the second-degree participants demonstrated a pattern of superior performance with regards to evaluative actions such as establishing level of consciousness, asking the patient questions regarding symptoms, checking the patient's airway, and noting the oxygen saturation rate. The traditional participants on the other hand assessed the patient's lung sounds, initiated calls for help and a code blue, and intervened to titrate the vasoactive medication earlier than the second-degree participants.

In Trial 2 participants were presented with a patient suffering from acute sepsis, with hypotension, on a norepinephrine infusion. During this scenario, only one assessment parameter, questioning the patient about symptom patterns, yielded significant results $(p<.05)$ in favor of second-degree participants. However, the second-degree participants demonstrated a pattern of superior performance by initiating all assessments and interventions in a timelier manner than their traditional counterparts, including the titration of vasoactive medications.

Differences in participants' performance of specific tasks and their time of occurrence in seconds for Trial 3 and Trial 4 are presented in Table 3. In Trial 3, the participant encountered a patient who had fallen and sustained a closed head injury. In this scenario, the second-degree participants again demonstrated a pattern of superiority performance in initiating key actions earlier. Two assessment parameters were statistically significant; the second degree participants more rapidly noted the patient's head wound $(p<.05)$ and the presence of pupil dilation, referred to as a blown pupil $(p<.05)$ The ability of participants to note these stimuli was key to a successful outcome for the patient in this scenario. 
Table 2. Comparison of traditional versus second-degree students on trials 1-2

\begin{tabular}{|c|c|c|c|c|}
\hline \multirow{2}{*}{ Variable } & \multicolumn{2}{|l|}{ Trial 1} & \multicolumn{2}{|l|}{ Trial 2} \\
\hline & Traditional BSN & Second Degree & Traditional BSN & Second Degree \\
\hline Establishes LOC & 88.42 (SD 83.72) & 13.38 (SD 14.75)* & 84.92 (SD 85.68) & 38.38 (SD 57.52) \\
\hline Questions regarding symptoms & 88.50 (SD 83.63) & $78.50(\mathrm{SD} 86.44)$ & 84.14 (SD 85.05) & $17.25(\mathrm{SD} 7.92)^{*}$ \\
\hline Checks airway & $176.17(\mathrm{SD} 8.14)$ & $170.63(\mathrm{SD} 26.52)$ & $167.67(\mathrm{SD} 36.64)$ & $158.63(\mathrm{SD} 37.49)$ \\
\hline Assess resp. rate & $179.25(\mathrm{SD} 62.50)$ & $179.50($ SD 21.41) & $152.25(\mathrm{SD} 56.05)$ & $139.13($ SD 56.48) \\
\hline Auscultates lungs & 76.58 (SD 66.57) & $113.75($ SD 70.01$)$ & $136.67(\mathrm{SD} 64.82)$ & $105.25(\mathrm{SD} 63.96)$ \\
\hline Notes O2 saturation & $140.00($ SD 61.57$)$ & $106.00(\mathrm{SD} 67.35)$ & 146.92 (SD 61.62) & $123.00($ SD 72.73) \\
\hline Notes blood pressure & 80.75 (SD 75.42) & 81.25 (SD 68.30) & 100.42 (SD 76.93) & $68.13(\mathrm{SD} 65.45)$ \\
\hline Calls for help & $148.08(\mathrm{SD} 44.64)$ & $167.88($ SD 32.32) & $170.50($ SD 33.22) & 169.50 (SD 22.19) \\
\hline Calls Code blue & $160.92(\mathrm{SD} 24.15)$ & $171.38(\mathrm{SD} 17.23)$ & $164.75(\mathrm{SD} 30.83)$ & $143.88(\mathrm{SD} 48.55)$ \\
\hline Notes head wound & $\mathrm{n} / \mathrm{a}$ & $\mathrm{n} / \mathrm{a}$ & $\mathrm{n} / \mathrm{a}$ & $\mathrm{n} / \mathrm{a}$ \\
\hline Notes enlarged pupil & $\mathrm{n} / \mathrm{a}$ & $\mathrm{n} / \mathrm{a}$ & $\mathrm{n} / \mathrm{a}$ & $\mathrm{n} / \mathrm{a}$ \\
\hline Notes bloody dressing & $\mathrm{n} / \mathrm{a}$ & $\mathrm{n} / \mathrm{a}$ & $\mathrm{n} / \mathrm{a}$ & $\mathrm{n} / \mathrm{a}$ \\
\hline
\end{tabular}

During Trial 4, the participant was assigned the care of a patient experiencing abdominal bleeding following gastrointestinal surgery. The key task associated with this trial was the identification of the presence of the bloody dressing indicating hemorrhage. The second-degree participants clearly outperformed the traditional group by identifying the bloody dressing more quickly $(p<.05)$. Further, although not statistically significant, the second-degree participants initiated the majority of evaluative actions earlier than traditional participants.

Table 3. Comparison of traditional versus second-degree students on trials 3-4

\begin{tabular}{|c|c|c|c|c|}
\hline \multirow{2}{*}{ Variable } & \multicolumn{2}{|l|}{ Trial 3} & \multicolumn{2}{|l|}{ Trial 4} \\
\hline & Traditional BSN & Second Degree & Traditional BSN & Second Degree \\
\hline Establishes LOC & 38.38 (SD 57.52) & 90.17 (SD 80.05) & 56.00 (SD 76.79) & 44.38 (SD 58.96) \\
\hline Questions regarding symptoms & $17.25(\mathrm{SD} 7.92)^{*}$ & 113.33 (SD 82.66) & $117.88(\mathrm{SD} 85.91)$ & 15.63 (SD 6.52) \\
\hline Checks airway & $158.63(\mathrm{SD} 37.49)$ & 139.25 (SD 62.15) & 134.25 (SD 63.67) & 177.58 (SD 27.33) \\
\hline Assess resp. rate & 139.13 (SD 56.48) & 133.25 (SD 66.75) & $111.23(\mathrm{SD} 34.26)$ & 161.38 (SD 52.68) \\
\hline Auscultates lungs & 105.25 (SD 63.96) & 173.17 (SD 10.97) & $156.13(\mathrm{SD} 43.70) *$ & $138.88(\mathrm{SD} 67.04)$ \\
\hline Notes O2 saturation & 123.00 (SD 72.73) & $160.75(\mathrm{SD} 36.33)$ & $131.63(\mathrm{SD} 48.04)$ & $155.38(\mathrm{SD} 48.74)$ \\
\hline Notes blood pressure & 68.13 (SD 65.45) & 118.58 (SD 51.48) & 88.38 (SD 46.94) & 72.25 (SD 51.69) \\
\hline Calls for help & 169.50 (SD 22.19) & 73.58 (SD 78.85) & 99.88 (SD 73.79) & $161.63(\mathrm{SD} 43.10)$ \\
\hline Calls Code blue & 143.88 (SD 48.55) & 158.83 (SD 42.72) & 146.75 (SD 65.01) & 161.37 (SD 48.39) \\
\hline Notes head wound & $\mathrm{n} / \mathrm{a}$ & 62.33 (SD 72.17) & $20.75($ SD 13.82)* & $\mathrm{n} / \mathrm{a}$ \\
\hline Notes enlarged pupil & $\mathrm{n} / \mathrm{a}$ & 152.33 (SD 50.28) & 80.75 (SD 52.54)* & $\mathrm{n} / \mathrm{a}$ \\
\hline Notes bloody dressing & $\mathrm{n} / \mathrm{a}$ & $\mathrm{n} / \mathrm{a}$ & $\mathrm{n} / \mathrm{a}$ & $53.00(\mathrm{SD} 34.48) *$ \\
\hline
\end{tabular}

\section{Discussion}

The research question addressed in the study was: How do second-degree baccalaureate nursing students differ from traditional baccalaureate nursing students in their ability to recognize and respond to salient stimuli in the management of deteriorating patients in a simulated task environment? The participants in the current study were not unique, relative to the limited comparative studies of traditional and second-degree baccalaureate students available in the literature. That is, the second-degree participants were generally 142 older, highly motivated students with a record of superior academic achievement, which concurs with the literature on second-degree students. ${ }^{[4-7]}$ Their lower cumulative versus nursing GPA averages compared to traditional students in this study is in part due to the proportion of second-degree students ( $\mathrm{n}=5$ or $25 \%)$ admitted to the program with baccalaureate degrees in the sciences (e.g. biology, chemistry and exercise physiology).

Data processing involved the quantification of key tasks performed by the participants and testing for significant inter- 
group differences in performance in the simulated task environment. Trial 1 yielded no statistically significant performance differences but significant differences arose during Trial 2, Trial 3 and Trial 4. In Trial 2, second-degree students questioned the patient about their symptoms earlier in the scenario than the traditional baccalaureate students $(p<.05)$. During Trial 3, the second-degree students were far more likely to note the presence of the head wound $(p<$ $.05)$ and the blown pupil $(p<.05)$. In Trial 4 , the seconddegree participants noted the presence of the bloody dressing at the patient's surgical site considerably earlier than their traditional counterparts $(p<.05)$.

One must consider the nature of the scenarios in order to fully understand the results of each trial. During Trial 1 and Trial 2 , the participants had several primary stimuli that required attention. These were the patient's cardiovascular state and the necessity of titrating the vasoactive drip. Given the similarity in the two trials, the consistent pattern of superior performance in the second-degree participants compared to the traditional participants in Trial 2, likely reflects a greater learning effect on their ability to identify and focus on salient information in the patient environment in a timelier manner. Further, while the action of asking questions regarding the patient's symptoms was only significant in Trial 2, it is notable that the second-degree students were more inclined to engage with the patient interpersonally as a component of their assessment.

In Trial 3 and Trial 4 there were important visual stimuli present in the environment that had to be recognized by the participant and acted upon. The statistically significant results in Trial-3 and Trial-4 reflect a clear superiority on the part of the second-degree students in fully apprehending the presence of key stimuli. The characteristics of the stimuli in the simulated task environment and their relationship to performance have been clearly documented in the literature. ${ }^{[35-37]}$ The results of the current study mirror those seen in studies of nurses with different levels of experience (e.g., novice versus expert), with the performance by the second-degree students reflecting the performance of more experienced practitioners. ${ }^{[35,38]}$ Overall, the performance differences seen between the two groups are supportive of the notion that second-degree programs develop individuals with key advantages in decision-making capacity. ${ }^{[19]}$

\section{Conclusion}

The results of the study indicate that second-degree students have attributes that increase the likelihood that they will appreciate stimuli in the clinical environment, which is a precursor to effective intervention. It is not clear which factors differentiate them the most. Possibilities include their age, greater educational achievement (having completed a previous degree) and differences in the delivery of second-degree and traditional baccalaureate programs. More research is required to substantiate the factors that account for performance differences between these groups. It is clear, nonetheless, that the initiative to prepare second-degree students in an expedited manner (most programs offer them an accelerated track) is efficacious, in that it produces individuals who have performance advantages over individuals in traditional programs. This is good news for employers and for the nursing workforce in general, since these programs speed entry to practice.

Second-degree accelerated programs are a relatively recent development in nursing education. In the future, more research is required to delineate the source of performance advantages. It is clear, however, that these programs are efficacious with regards to educating high-quality entry-level practitioners. Given the popularity of these programs, this is optimistic for the profession.

\section{CONFlicts of InTEREST Disclosure}

The authors declare that they have no competing interests.

\section{REFERENCES}

[1] Stuenkel D, Nelson D, Malloy S, et al. Challenges, changes, and collaboration: Evaluation of an Accelerated BSN Program. Nurse Educator 2011; 36(2): 70-75. http://dx . doi .org/10.1097/NNE $.0 \mathrm{~b} 013 \mathrm{e} 31820 \mathrm{c} 7 \mathrm{cf} 7$

[2] Raines DA. Five years later: Are accelerated, second-degree program graduates still in the workforce? International Journal of Nursing Scholarship. 2013; 10 (1): 1-6. http://dx.doi.org/10.1515/i jnes-2012-0035

[3] Lindsey P. Educational innovations. Starting an accelerated baccalaureate nursing program: challenges and opportunities for creative educational innovations. Journal of Nursing Education. 2009; 48(5):
279-281. PMid:19476033.

[4] American Association of Colleges of Nursing AACN). Available from: http://www . aacn.nche.edu/education-resources/b accessentials08.pdf (18 September 2015, date last accessed).

[5] Bentley R. Comparison of traditional and accelerated baccalaureate nursing graduates. Nurse Educator. 2006; 31(2): 79-83. PMid:16601615. http://dx.doi.org/10.1097/00006223-200 603000-00010

[6] Korvick L, Wisener L, Loftis L, et al. Comparing the academic performance of students in traditional and second-degree baccalaureate programs. Journal of Nursing Education. 2008; 47(3): 139-141. http://dx.doi.org/10.3928/01484834-20080301-10 
[7] Newton SE, Moore G. Critical thinking skills of basic baccalaureate and accelerated second-degree nursing students. Nursing Education Perspectives. 2013; 34(3): 154-158. http://dx.doi.org/10.54 80/1536-5026-34.3.154

[8] Penprase B, Koczara S. Understanding the experiences of accelerated second-degree nursing students and graduates: a review of literature. Journal of Continuing Education in Nursing. 2009; 40(2): 74-78. http://dx.doi.org/10.3928/00220124-20090201-08

[9] Cangelosi PR. Accelerated nursing students and theater students: Creating a safe environment by acting the part. Nursing Education Perspectives. 2008; 29(6): 342-346. PMid:19244799.

[10] Cangelosi P, Whitt K. Accelerated nursing programs: what do we know? Nursing Education Perspectives. 2005; 26(2): 113-116. PMid:15921128.

[11] Walker JT, Martin TM, Haynie L, et al. Preferences for teaching methods in a baccalaureate nursing program: How second-degree and traditional students differ. Nursing Education Perspectives. 2007; 28(5): 246-250.

[12] Simko LC, Henry R, McGinnis KA, et al. Simulation and mock code: A safe way for nursing students to learn. Journal of Nursing Education and Practice. 2014; 4(7): 95. http://dx.doi.org/jne p.v4n7p95

[13] Benner P, Sutphen M, Leonard V, et al. Educating nurses: A call for radical transformation. John Wiley \& Sons. 2009; 15.

[14] Institute of Medicine (US). Committee on the Robert Wood Johnson Foundation Initiative on the Future of Nursing. The future of nursing: Leading change, advancing health. National Academies Press; 2011

[15] Goode C, Williams C. Post-baccalaureate nurse residency program. Journal of Nursing Administration. 2004; 34(2): 71-77. PMid:14770065. http://dx.doi.org/10.1097/00005110-200 402000-00004

[16] McKenna L, Missen K, Cooper S, et al. Situation awareness in undergraduate nursing students managing simulated patient deterioration. Nurse Education Today. 2014; 34(6): e27-31. http: //dx.doi.org/10.1016/j.nedt.2013.12.013

[17] Cooper S, Beauchamp A, Bogossian F, et al. Managing patient deterioration: a protocol for enhancing undergraduate nursing students' competence through web based simulation and feedback techniques. BMC Nursing. 2012; 11(1): 18-24. http://dx.doi.org/10.11 86/1472-6955-11-18

[18] Gillespie M, Peterson B. Helping novice nurses make effective clinical decisions: the situated clinical decision-making framework. Nursing Education Perspectives. 2009; 30(3): 164-170. PMid:19606659.

[19] Porr C, Brennan-Hunter A, Crossman R, et al. Revolutionizing an accelerated baccalaureate nursing curriculum. Journal of Nursing Education and Practice. 2014; 4(9): 183. http://dx.doi.org/j nep.v4n9p183

[20] Lapkin S, Levett-Jones T, Bellchambers H, et al. Effectiveness of patient simulation manikins in teaching clinical reasoning skills to undergraduate nursing students: A systematic review. Clinical Simulation in Nursing. 2010; 6(6): e207-e222. http://dx.doi.org/1 $0.1016 /$ j.ecns. 2010.05 .005

[21] Gore T, Leighton K, Sanderson B, et al. Fidelity's Effect on Student Perceived Preparedness for Patient Care. Clinical Simulation in Nursing. 2014; 10(6): e309-e315. http://dx.doi.org/10.1016/j.e cns. 2014.01.003

[22] Weaver A. High-fidelity patient simulation in nursing education: An integrative review. Nursing Education Perspectives. 2011; 32(1): 37-40. http://dx.doi .org/10.5480/1536-5026-32.1.37

[23] Yuan HB, Williams BA, Fang JB. The contribution of high-fidelity simulation to nursing students' confidence and competence: a sys- tematic review. International Nursing Review. 2012; 59(1): 26-33. http://dx.doi.org/10.1111/j.1466-7657.2011.00964.x

[24] Alinier G, Platt A. International overview of high-level simulation education initiatives in relation to critical care. Nursing in Critical Care. 2014; 19(1): 42-49. http://dx.doi.org/10.1111/nicc. 12030

[25] Kirkman TR. High fidelity simulation effectiveness in nursing students' transfer of learning. International Journal of Nursing Education Scholarship. 2013; 10(1): 1-6.

[26] Boellaard MR, Brandt CL, Johnson NL, et al. Practicing for Practice: Accelerated Second Baccalaureate Degree Nursing (ABSN) Students Evaluate Simulations. Nursing Education Perspectives. 2014; 35(4): 257-258. PMid:25158421. http://dx.doi.org/10.5480/12-8 47.1

[27] Piscotty R, Grobbel C, Tzeng HM. Integrating quality and safety competencies into undergraduate nursing using student-designed simulation. The Journal of Nursing Education. 2011; 50(8): 429-436. PMid:21534498. http://dx.doi.org/10.3928/01484834-201 10429-04

[28] Onello R, Regan M. Challenges in high fidelity simulation: Risk sensitization and outcome measurement. Online Journal of Issues in Nursing. 2013; 18(3): 1. http//dx.doi.org/10.3912/0JIN. Vo 118No03PPT01

[29] Bogossian F, Simon C, Robynet C, et al. Undergraduate nursing students' performance in recognizing and responding to sudden patient deterioration in high psychological fidelity simulated environments: An Australian multi-center study. Nurse Education Today. 2014; 34(5): 691-696. PMid:24183634. http://dx.doi.org/10.1016 /j.nedt.2013.09.015

[30] Radhakrishnan K, Roche J, Cunningham H. Measuring clinical practice parameters with human patient simulation: a pilot study. International Journal of Nursing Education Scholarship. 2007; 4(1): 1-11. http://dx.doi.org/10.2202/1548-923X.1307

[31] Blum CA, Susan Borglund S, Parcells D. High-fidelity nursing simulation: Impact on student self-confidence and clinical competence. International Journal of Nursing Education Scholarship. 2010; 7(1) http://dx.doi.org/10.2202/1548-923X. 2035

[32] Ericsson KA, Krampe RT, Tesch-Romer C. The role of deliberate practice in the acquisition of expert performance. Psychological Review. 1993; 100 (3): 363-406. http://dx.doi.org/10.1037/0 033-295X.100.3.363

[33] Whyte J, Ward P, Eccles D. The relationship between knowledge and clinical performance in novice and experienced critical care nurses: An application of the Expert Performance Approach. Heart \& Lung 2009; 38(6): 517-525. http://dx.doi.org/10.5430/jnep.v4 $\mathrm{n} 11 \mathrm{p} 74$

[34] Ericsson KA, Simon HA. Verbal reports as data. Psychological Review. 1980; 87(3): 215-251. http://dx.doi.org/10.1037/003 3-295X.87.3.215

[35] Aitken LM, Marshall AP, Elliott R, et al. Critical care nurses' decision making: sedation assessment and management in intensive care. Journal of Clinical Nursing. 2009; 18(1): 36-45. http: //dx.doi.org/10.1111/j.1365-2702.2008.02318.x

[36] Hedberg B, Larsson U. Observations, confirmations and strategies - useful tools in decision-making process for nurses in practice? Journal of Clinical Nursing. 2003; 12(2): 215-222. http: //dx.doi.org/10.1046/j.1365-2702.2003.00703.x

[37] Cioffi J, Conway R, Everist L, et al. 'Changes of concern' for detecting potential early clinical deterioration: A validation study. Australian Critical Care. 2010; 23(4): 188-196.

[38] Tingsvik C, Johansson K, Martensson J. Weaning from mechanical ventilation: factors that influence intensive care nurses' decision-making. Nursing in Critical Care. 2015; 20(1): 16-24. PMid:25269708. http://dx.doi.org/10.1111/nicc.12116 